\title{
O poder da linha na construção dos sentidos: uma análise a partir dos vários aspectos da cruz
}

\author{
Power line construction of the senses: \\ from an analysis of various aspects of the cross
}

Carvalho, Mariane Oliveira de; Especialista;

Faculdade Pitágoras - Unidade Metropolitana

mari_de_carvalho@yahoo.com.br

Gomes, Rogério Zanetti; Mestre;

Faculdade Pitágoras - Unidade Metropolitana

rogerioghomes@gmail.com

\begin{abstract}
RESUMO
Este artigo apresenta um estudo sobre a cruz, uma das mais antigas formas criadas pelo homem, e discute seu conhecimento culturalmente produzido na consciência coletiva. Buscou-se verificar quais das suas formas são mais lembradas, investigando que conotação estas exercem sobre as pessoas. $\mathrm{O}$ uso de símbolos no design pode ser um ótimo aliado para a geração de sensações nos receptores, sendo boas ou chocantes, entretanto deve-se ter a preocupação de transmiti-las de forma adequada, de modo que não haja ambiguidade.
\end{abstract}

Palavras Chaves: Iconografia; Símbolo; Cultura; Cruz.

\begin{abstract}
This article presents a study on the cross, one of the oldest forms created by man, and discusses their cultural knowledge produced in the collective consciousness. We sought to determine which of their forms are more memorable, investigating connotation that they impose on the people. The use of symbols in the design can be a great ally for the generation of sensations the receivers, good, or shocking, however you must take care to pass them properly, so there is no ambiguity.
\end{abstract}

Keywords: Iconography; Symbol; Culture; Cross.

\section{Introdução}

A sociedade encontra-se cicatrizada por diversos acontecimentos histórico-culturais que, por carregarem um forte significado, contribuem para o conhecimento do passado e influenciam o modo de viver contemporâneo.

Muitas são as formas como cada pessoa compreende o que está implícito ou explícito nas linhas que foram constituídas e articuladas para expressar significados.

Ampliar o conhecimento sobre essa percepção particular e, ao mesmo tempo, do senso comum, é importante para que se obtenha maior eficiência na comunicação, tornando-se possível adequar o símbolo à mensagem, com qualidade, funcionalidade e arte.

Com esse objetivo, o presente estudo busca discutir o conhecimento culturalmente produzido sobre a cruz, uma das mais antigas formas criadas e consagradas pelo homem, ao longo da história, como um signo de forte ressonância na consciência coletiva. Assim, buscou-se verificar quais das suas formas de representação são mais lembradas e que conotação estas exercem sobre as pessoas. 
No design, é extremante importante uma reflexão sobre este assunto, pois o mesmo está relacionado à área da comunicação. Conforme Villas-Boas:

(...) nasce da necessidade de, num ambiente de massas, agregar valores simbólicos a determinados bens, sejam estes concretos ou não. Para tal, lança mão de um instrumental simbólico que se expressa materialmente no plano da visualidade, de forma a veicular estes valores mediante a preservação deste mesmo caráter simbólico (VILLAS-BOAS, 2002, p. 19).

Neste sentido, Melo assinala que:

Nossa atividade profissional é uma intervenção no cotidiano das pessoas, das empresas, das instituições, dos governos, da sociedade. Ter consciência da origem dos problemas para os quais somos chamados a apresentar soluções é um ponto de partida necessário e fundamental (MELO, 2005, p. 64).

O presente estudo foi estruturado em três (3) etapas:

A primeira apresenta um levantamento bibliográfico das principais contribuições científicas existentes sobre os temas: design, iconografia, símbolo, cultura, cruz e imagem. Vale salientar, entretanto, que não se tem a pretensão de esgotar os temas relacionados, mas sim contribuir com possíveis reflexões acerca da utilização dos símbolos no meio comunicacional.

Na segunda etapa, apresenta-se a pesquisa de campo, efetivada por meio de um questionário digital", produzido com o auxílio da ferramenta "Google Docs". O questionário, composto por questões qualitativas e quantitativas, abertas e fechadas, foi aplicado a um público direcionado de vinte e seis (26) formadores de opinião, das áreas de Artes, Comunicação e Humanas, membros integrantes da rede de relacionamentos dos autores.

O questionário teve como objetivo verificar:

1a Parte (IDENTIFICAÇÃO)

O sexo dos participantes;

a. A faixa-etária: menor que 20 anos - entre 20 e 39 anos - entre 40 e 59 anos - acima de 60 anos;

b. A formação / graduação dos participantes;

c. O nível de formação: pós-graduação: especialização, mestrado ou doutorado.

d.

\section{2a Parte (QUESTÕES)}

1. Apresentação de imagens dos símbolos: cruz simples - cruz de Santo Antônio (Tau) - cruz Ansata - cruz Gamada (Suástica) - cruz de Malta - cruz Cristã - cruz de Santo André - Cruz Rosa-cruz - Cruz de Jerusalém. Pediu-se que os participantes identificassem os símbolos por eles conhecidos;

2. Solicitou-se que descrevessem as semelhanças gráficas entre os símbolos da questão anterior;

3. Questionou-se se os participantes conheciam algum material gráfico ou evento que tenha utilizado o símbolo da cruz como auxílio à divulgação/ propaganda. Pediu-se aos que afirmaram conhecer, que relacionassem quais;

4. Perguntou-se se os participantes utilizariam o símbolo da cruz para vender algum tipo de produto ou serviço e de que forma o fariam;

5. Questionou-se que conotação, positiva ou negativa, acreditam que o símbolo da cruz exerce; e solicitou-se que esclarecessem a posição apresentada.

Na terceira e última etapa da pesquisa, realizou-se uma articulação entre a revisão bibliográfica e os resultados obtidos pela pesquisa de campo. 


\section{Design}

Embora existam inúmeras discussões sobre o tema, pode-se compreender o design como o resultado da prática da relação entre várias linguagens, como, por exemplo, o uso da criatividade junto com a tecnologia. Pra Schneider:

(...) é a visualização criativa e sistemática dos processos de interação e das mensagens de diferentes atores sociais; é a visualização criativa e sistemática das diferentes funções dos objetos de uso e sua adequação às necessidades dos usuários ou aos efeitos sobre os receptores. (SCHNEIDER, 2010, p. 197)

Antes de tudo, design é algo que se planeja, projeta, como afirma Alexandre Wollner, "Design é projeto". (STOLARSKI, 2005, p.67) Assim, o propósito é um dos pontos que o diferencia da arte. 0 design veio para solucionar problemas externos, propostos pela sociedade, enquanto a arte visa a resolver problemas que o próprio artista determinou. (MELO, 2005)

Flusser (2007, p. 181) apresenta algumas definições sobre a palavra design que, em inglês, funciona como substantivo e verbo. Como substantivo, destacam-se os seguintes significados: propósito, plano, intenção e meta. Como verbo - to design -, pode significar projetar, esquematizar, configurar, proceder de modo estratégico. Segundo Moura:

Criar, desenvolver, implantar um projeto - o design - significa pesquisar e trabalhar com referências culturais e estéticas, com o conceito da proposta. É lidar com a forma, com o feitio, com a configuração, a elaboração, o desenvolvimento e o acompanhamento do projeto.(MOURA, 2003, p. 118).

\section{Iconografia}

Segundo Carrion (2008, p. 153), a palavra iconografia "pode ser traduzida literalmente como "escrita de imagem". Do grego "Eikon" (imagem) e "Graphia" (escrita), seu uso está ligado à criação de projetos (design), ao simbolismo e à igreja".

Pode-se entendê-la como uma das linguagens utilizadas a favor da comunicação dentro das diferentes culturas, com uma variação, em sua aplicação, conforme as crenças e os valores socioculturais vigentes.

Carrion (2008) pontua alguns aspectos muito importantes dentro da iconografia: a leitura deve ser simplificada para que não haja interferência na compreensão; a imagem pode se utilizar da descrição simbólica relativa à cultura; pode ser classificada de várias formas, tomando-se como base, por exemplo, os aspectos: cultural, ilustrativo e religioso.

\section{Símbolo}

Rand (1942 apud HURLBULT, 2002, p.72) define símbolo como "linguagem comum entre o artista e o observador" que pode ser representada "por uma forma abstrata, uma figura geométrica, uma fotografia, uma ilustração, uma letra do alfabeto, um número". O autor complementa que esta é uma linguagem que está em destaque desde as primeiras manifestações culturais.

Pode-se compreender símbolo como aquilo que é convencionado, que pode substituir qualquer coisa, independente do formato, e ainda assim ser compreendido.

Vale ressaltar que deve haver uma preocupação para que se faça a melhor escolha para a expressão da representação de um símbolo, para que este, de fato, atinja o público-alvo.

Hurlbult $(2002$, p.72) exemplifica a cruz como um dos primeiros símbolos de importância mundial, assim como a flecha.

\section{Cultura}


Segundo Laraia (2008, p.14), o termo Cultura, sintetizado por Edward Tylor (1832-1917), no vocábulo inglês Culture, uniu as palavras "Kultur" e "Civilization". Anteriormente, o termo germânico "Kultur" era utilizado para simbolizar todos os aspectos espirituais de uma comunidade, enquanto a palavra francesa "Civilization" estava relacionada às realizações materiais de um povo.

O dicionário Houaiss (2001)² define cultura como:

[...] Conjunto dos conhecimentos adquiridos; a instrução, o saber: uma sólida cultura. / Sociologia Conjunto das estruturas sociais, religiosas etc., das manifestações intelectuais, artísticas etc., que caracteriza uma sociedade: a cultura inca; a cultura helenística. / Aplicação do espírito a uma coisa: a cultura das ciências. / Desenvolvimento das faculdades naturais: a cultura do espírito. / Apuro, elegância: a cultura do estilo. // Cultura de massa, conjunto dos fatos ideológicos comuns a um grupo de pessoas consideradas fora das distinções de estrutura social, e difundidos em seu seio por meio de técnicas industriais. // Cultura física, desenvolvimento racional do corpo por exercícios apropriados.

Pode-se considerar cultura como todo comportamento aprendido, ou seja, como tudo aquilo que independe de uma transmissão genética e que se apreende por meio do contato com as pessoas e da participação em determinados grupos sociais.

Segundo Villas-Boas (2002, p. 56), a primeira acepção de cultura teve origem no meio rural e se referia ao cultivo agrícola, pois se tratava de um sistema de plantação que se desenvolvia a partir da interseção dos seguintes fatores: as propriedades da terra, o clima e eventuais ocorrências de outros fenômenos à sua volta, ou seja, de um sistema que dependia do que acontecia ao mesmo tempo e no mesmo local.

Pode-se compreender, então, que há singularidades em cada cultura e estas são determinadas por fatores como espaço e tempo. Desse modo, cada cultura nasce e se desenvolve de um modo particular, pois, ao agregar valores do meio, torna-se criadora de sua essência cultural e fonte de estudo. Isto justifica a performance da cultura atual, cuja organização social inclui as chamadas "tribos", que fazem uso de símbolos e frases para se comunicar e marcar território.

Entre os inúmeros exemplos culturais que se pode citar, estão os "Cristãos" e os "Nazistas", que se contrapõem em opiniões culturais devido às suas raízes.

Villas-Boas, ao analisar a relação entre a cultura e o design gráfico, reflete que:

Todos nós lidamos com as relações do projeto gráfico com a cultura e com a contemporaneidade no nosso próprio dia a dia como designers: quando elaboramos um projeto, dois fatores que levamos em conta é o cliente e o público-alvo. Ou melhor ainda: o discurso do cliente e o discurso do publico alvo. São estes dois discursos que temos de considerar para a eles submeter outras variáveis da situação de projeto (processos de produção, orçamentos, cronogramas etc) e chegar a soluções dadas como compatíveis e viáveis. (VILLAS-BOAS, 2002, p. 18)

Villas-Boas (2002) afirma que o design não é apenas uma atividade integrante da cultura contemporânea, mas é um de seus elementos mais vivazes, justamente porque é capaz de sinalizar a cota do espaço e do tempo, na atualidade. Um projeto gráfico denota, necessariamente, o contexto simbólico no qual está inserido.

\section{Cruz}

A cruz é um dos símbolos mais antigos da humanidade. "[...] cuja presença é atestada desde a mais alta Antiguidade: no Egito, na China, em Cnossos, Creta, onde se encontrou uma cruz de mármore do séc. XV, a.C." (CHEVALIER e GHEERBRANT, 1995, p. 309)

Para Hurlbult (2002, p.72), a cruz representa "um dos principais símbolos de importância 
mundial. Ao lado de conotações simples - conformismo/ agressividade, homem/mulher, terra/céu -, esse símbolo também tem uma forma simples e simétrica".

A cruz é um símbolo de forma geométrica simples, que possui a intersecção de linhas de eixos opostos (vertical e horizontal) e a presença de ângulos perpendiculares. Segundo Frutiger:

(...) o ponto de intersecção entre as duas linhas traz algo de abstrato, na verdade invisível, porém tão preciso, que matemáticos, arquitetos, geógrafos, geólogos, entre outros, utilizam-no frequentemente para designar a posição exata de um ponto (...) (FRUTIGER, 1999, p.29).

"O ponto indica uma posição no espaço. Em termos puramente geométricos, um ponto é um par de coordenadas x e y. Ele não possui massa alguma. Graficamente, contudo, um ponto toma forma como um sinal, uma marca visível." (LUPTON, E. 2008 p. 15). Nesse sentido, Frutiger assinala que:

Diante de um sinal de "mais", o observador permanece neutro. Porém, basta alongar ligeiramente um ou outro braço para o sinal perder sua transparência e dar lugar a reações psicológicas. A alteração mais marcante forma-se com o alongamento da vertical para baixo. Desse modo, surge no mesmo instante o sinal da fé cristã. Por quase dois mil anos, a presença desse sinal marca profundamente todo o Ocidente. (FRUTIGER, 1999, p.29)

A verticalidade transmite a relação entre dois mundos, o celeste e o terrestre, como ressalta Frutiger:

Neste momento, gostaríamos apenas de observar que a proporção das horizontais colocadas em relevo é semelhantes à da figura humana (como a imagem inteira de Cristo na cruz) e que justamente por isso possui um profundo significado simbólico. (FRUTIGER, 1999, p.30)

A cruz é um símbolo que transmite equilíbrio. Para Lupton:

O equilíbrio é uma condição humana fundamental: precisamos de equilíbrio físico para ficar de pé e andar, buscamos equilíbrio entre as várias facetas de nossa vida pessoal e profissional, e o mundo luta pelo equilíbrio do poder. De fato, o equilíbrio é um conforto estimado em nossa cultura e não nos surpreende que nossa relação intuitiva, implícita com ele, nos tenha capacitado a perceber o equilíbrio - ou o desiquilíbrio - nas coisas que vemos, ouvimos, cheiramos, provamos ou tocamos. Em design, o equilíbrio age como uma baliza para a forma - ele ancora e ativa elementos no espaço. (LUPTON, 2008, p.29).

Frutiger (1999, p.29) considera a cruz como o "sinal dos sinais". Na matemática, é utilizada como um símbolo indicial de acréscimo (soma). Nesse sentido, Hurlbult (2002, p.72) afirma que “Hoje em dia, em nossa sociedade materialista, estamos convencidos de que, além de seu significado espiritual e religioso, a cruz pode ser vista como o sinal matemático de adição".

LUCCA $^{3}$ complementa que "é possível detectar a presença da cruz, seja de forma religiosa, mística ou esotérica, na história de povos distintos (e distantes) como os [...], celtas, persas, romanos, fenícios e índios americanos".

\section{Tipos de Cruz}

Os vários tipos de cruz nada mais são do que novas reorganizações gráficas que geram novos significados.

As diferentes formas de representação deste símbolo (variações angulares, deslocamentos) 
causam as mais diversas reações psicológicas nas pessoas. Frutiger $(1999$, p. 29) ressalta que para "comprovar o quanto esse sinal pode nos causar irritação e estranheza, basta colocar a horizontal abaixo do centro (cruz de São Pedro, que foi crucificado de cabeça para baixo)".

Vale salientar que as diferentes reações psicológicas são extremamente dependentes do repertório imagético-cultural do observador.

Abaixo, algumas das representações da cruz:

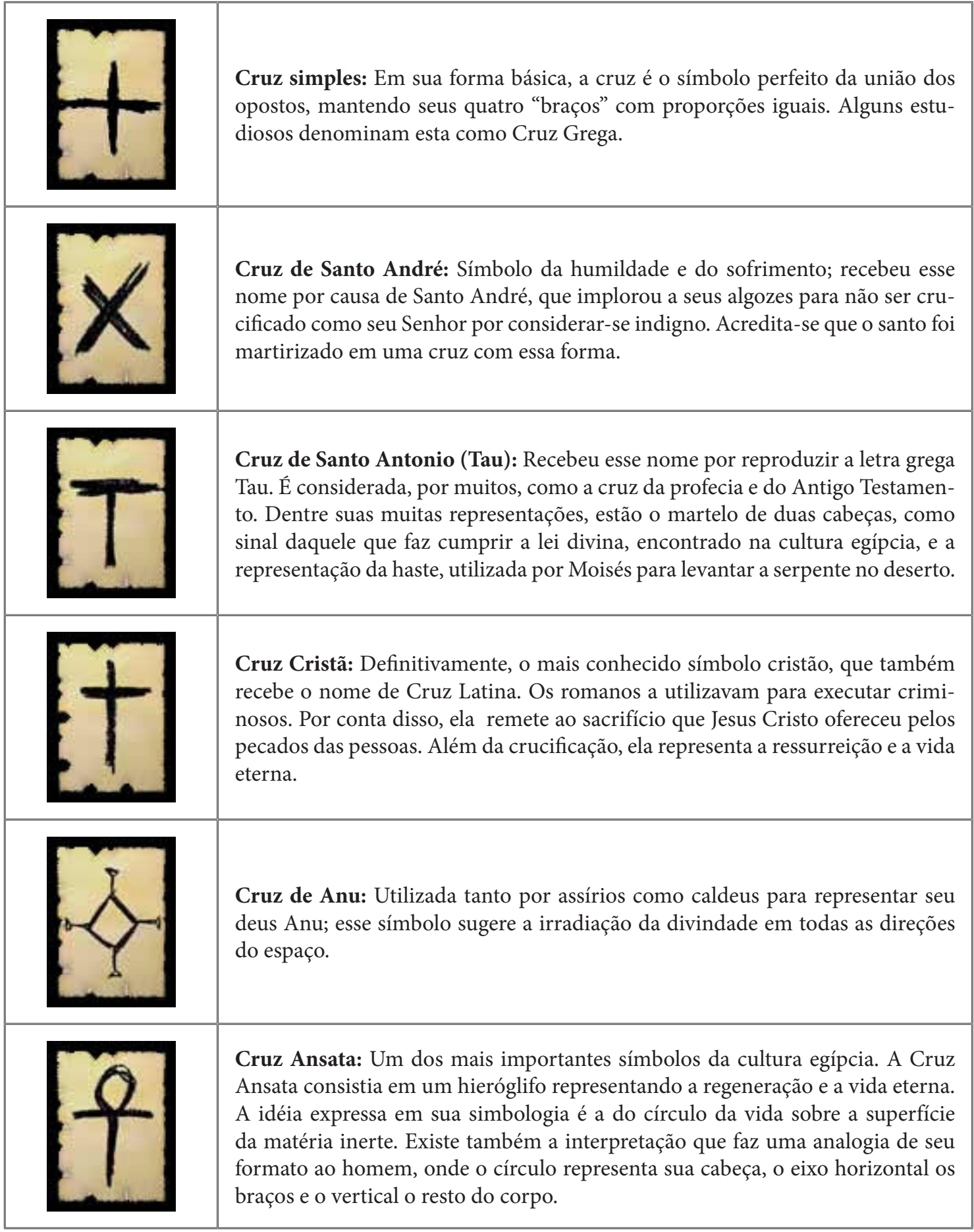




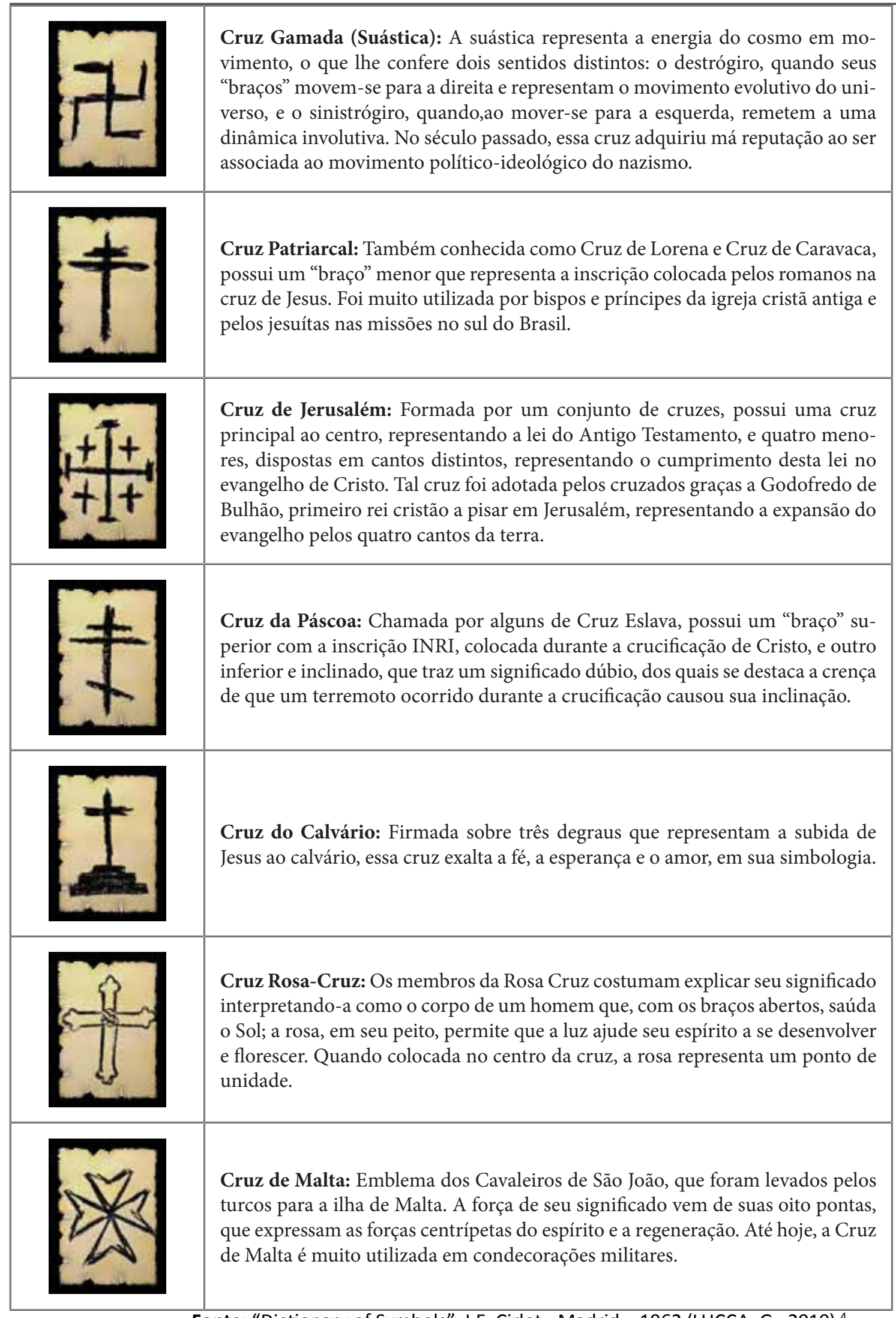

Fonte: “Dictionary of Symbols", J.E. Cirlot - Madrid - 1962 (LUCCA, G., 2010) ${ }^{4}$ 

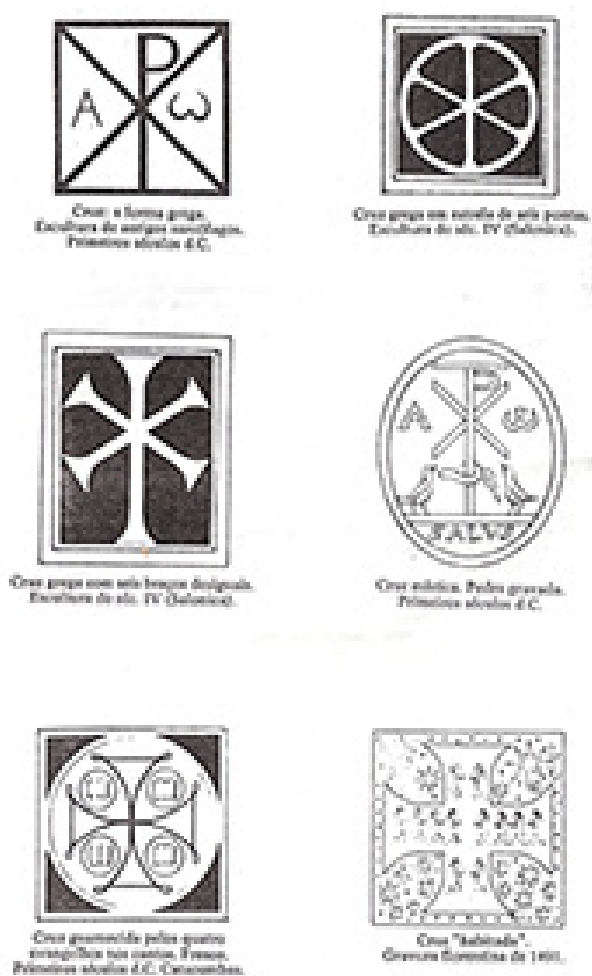

Fonte: Dicionário de símbolos: mitos, sonhos, costumes, gestos, formas, figuras, cores, números. (CHEVALIER, e GHEERBRANT, 1995, p. 316)<smiles>C1CCC2(C1)CCC2</smiles>

Cruz em forma de setas, indicando forças centrífugas.

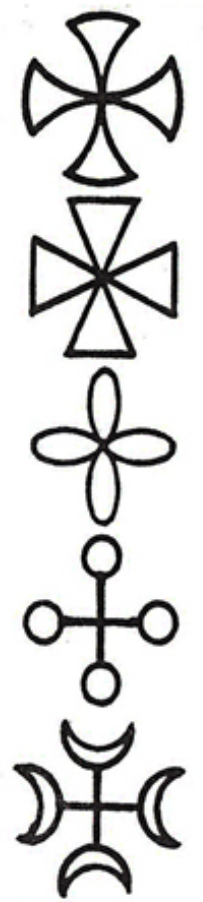

CRUZ DOS TEMPLÁRIOS: as forças dispostas em torno de uma circunferência.

CRUZ TEUTÔNICA: quatro triângulos que denotam uma tendência centrípeta.

CRUZ DE OVAIS: composta por um representante da linha contínua dá a direção do movimento das forças.

CRUZ COM CIRCUNFERENCIAS EM SUAS EXTREMIDADES: representam os quatro pontos cardeais.

CRUZ SEMILUNAR: (de acordo com Piob) representa as quatro circunferências tangentes e as fases da lua.

Fonte: A dictionary of Symbols (Cirlot,1990, p. 68-69) 
Para Cirlot (1990, p. 69), o simbolismo complexo da cruz não nega e nem substitui o sentido histórico do cristianismo. A cruz tem sido, amplamente, utilizada como um emblema gráfico, em grande parte, devido à influência cristã, mas, também, por seu amplo significado como símbolo.

\section{Imagem}

Basicamente, pode-se conceituar imagem como a representação visual de um objeto ou como o fruto de uma projeção mental.

Neiva Jr (1986, p.5) conceitua imagem como “[...] uma síntese que oferece traços, cores e outros elementos visuais em simultaneidade. Após contemplar a síntese é possível explorá-la aos poucos; só então emerge novamente a totalidade da imagem".

Para Aumont (1995, p.131), a "imagem é universal, mas sempre particularizada". Imagens visuais estão presentes em todos os lugares e fazem parte do cotidiano em qualquer sociedade.

Aumont estabelece três principais modos para se discutir a função das imagens:

a) O modo simbólico. Inicialmente as imagens serviram de símbolos, para ser mais exato, de símbolos religiosos, vistos como capazes de dar acesso à esfera do sagrado pela manifestação mais ou menos direta de uma presença divina. b) O modo epistêmico. A imagem traz informações (visuais) sobre o mundo, que pode assim ser conhecido, inclusive em alguns de seus aspectos não-visuais. c) $\mathrm{O}$ modo estético. $\mathrm{A}$ imagem é destinada a agradar seu espectador, a oferecer-lhe sensações (aisthésis) específicas (AUMONT, 1995, p. 80)

O primeiro ponto estabelecido por Aumont, no trecho acima, é entendido como semiótica. Santaella $(1983$, p. 2) define semiótica como a ciência que investiga todas as linguagens, ou seja, que examina como se constituem todos os fenômenos que produzem significado e sentido.

Quanto aos valores das imagens em sua relação com o real, Arnheim afirma:

a) Um valor de representação: a imagem representativa é a que representa coisas concretas [...]; b) Um valor de símbolo: a imagem simbólica é a que representa coisas abstratas [...]; c) Um valor de signo: para Arnheim, uma imagem serve de signo quando representa um conteúdo cujos caracteres não são visualmente refletidos por ela (ARNHEIM apud AUMONT, 1995, p. 78-79)

Aumont (1995) complementa que, em geral, a imagem tem como função essencial representar as simbologias da sociedade, pois se apresenta como mediadora entre a pessoa que a visualiza e a realidade.

\section{Resultados e Discussões}

\section{Identificação dos sujeitos da pesquisa}

Dos 26 participantes da pesquisa de campo, $58 \%$ são do sexo feminino e $42 \%$, do masculino.

Quanto à faixa-etária, $81 \%$ dos pesquisados têm entre 20 e 39 anos; 15\%, entre 40 e 59 anos; e $4 \%$ destes não responderam.

Quanto à formação, 8\% dos participantes possuem graduação em Administração de Empresas; 19\%, em Artes Visuais com ênfase em Multimídia; 4\%, em Arquitetura; 8\%, em Comunicação Social: Jornalismo; 10\%, em Comunicação Social: Relações Públicas; 23\%, em Design Gráfico; 4\%, em Direito; $4 \%$, em Geografia; 4\%, em Letras; 4\%, em Marketing e Propaganda; 4\%, em Sociologia; e $8 \%$ dos pesquisados não responderam.

Do total, 50\% são pós-graduados; destes, 38,5\% são especialistas e $11,5 \%$, mestres.

\section{Questões}

Na primeira questão, foram disponibilizadas imagens dos símbolos: cruz Simples, cruz de Santo 
Antônio (Tau), cruz Ansata, cruz Gamada (Suástica), cruz de Malta, cruz Cristã, cruz de Santo André, cruz Rosa-cruz e cruz de Jerusalém. Solicitou-se que os participantes identificassem os símbolos que conheciam, assinalando os campos correspondentes.

A soma das porcentagens ultrapassou $100 \%$ porque poderiam ser marcadas mais de uma caixa de seleção. Assim, $81 \%$ dos pesquisados assinalaram o campo da cruz Simples; $27 \%$, da cruz de Santo Antônio (Tau); 35\%, da cruz Ansata; $81 \%$, da cruz Gamada (Suástica); 46\%, da cruz de Malta; $100 \%$, da cruz Cristã; $11,5 \%$, da cruz de Santo André; $77 \%$, da cruz Rosa-Cruz; e 35\%, da cruz de Jerusalém.

Houve reconhecimento, por parte dos participantes da pesquisa de campo, de todos os símbolos disponibilizados. A cultura foi um fator determinante para o resultado obtido, visto que influenciou na identificação. Os acontecimentos históricos geram marcas e lembranças, desse modo, ainda que estejam apenas guardados na memória, veem à tona mediante a visualização de uma imagem / símbolo.

Na segunda questão, questionou-se as semelhanças gráficas entre os símbolos disponibilizados e se obteve o seguinte resultado: $15 \%$ dos participantes descreveram apenas linhas; $77 \%$ visualizaram a intersecção das linhas, a presença de perpendicularidade $\left(90^{\circ}\right.$ ), as formas simples e geométricas, enfim, as cruzes; $8 \%$ destes não responderam.

Resumidamente, o objetivo dessa questão foi atingido, pois o total dos participantes, mesmo que, de forma primária, reconheceu que todos os símbolos dispostos eram formas de representação da cruz.

Procurou-se verificar, na terceira questão, se os participantes conheciam algum material gráfico ou evento que tivesse utilizado a cruz como auxílio à divulgação. Caso conhecessem, solicitouse que os listassem.

Como resposta a essa questão, $65 \%$ dos participantes afirmaram ter presenciado, pelo menos, um material ou evento. Dentre estes, $4 \%$ citaram feiras de acessórios; $27 \%$, logomarcas, como: Suástica, Colégio Máxi, Cruz Vermelha e a marca farmacêutica Hexal; $46 \%$ citaram eventos e materiais gráficos ligados a igrejas; e 15\% lembraram de materiais gráficos ligados à II Guerra Mundial, relacionados ao nazismo (Gestapo - Polícia Secreta Prussinana).

Constatou-se que a estrutura gráfica do símbolo da cruz tem sido utilizada por designers, em diversos meios da comunicação visual, ainda que, em sua maioria, ligada à religião. Por ser um símbolo que tem sobrevivido ao longo dos anos, pode-se concluir que a sua estrutura é útil e eficaz para comunicar algo a alguém.

Na quarta questão, questionou-se se os participantes utilizariam o símbolo da cruz para vender algo; em caso positivo, de que forma fariam isso. Como resposta, $50 \%$ dos respondentes assinalaram sim; $42 \%$, não; e $8 \%$ destes disseram não saber.

Destes 50\%, 23\% responderam relacionando o símbolo a produtos cristãos; $8 \%$ afirmaram que o usariam da forma que lhes conviesse, dependendo do produto; $19 \%$ disseram que utilizariam em propagandas, como, por exemplo: em pedidos de ajuda humanitária, funerárias, livros, serviços médicos etc; $4 \%$, a partir de releituras; $4 \%$, por meio de grafismos; $4 \%$, em logomarcas; $4 \%$, em brasões (escudos ou times); $4 \%$ associaram a produtos destilados, como, por exemplo, o uísque, fazendo ligação do símbolo à Escócia; e 4\% afirmaram não desejar utilizar o símbolo da cruz para a comunicação de algo. Estes últimos alegaram que se a cruz estivesse ligada apenas a um elemento visual, ou seja, não tivesse a intenção de remeter a algum significado a alguém, a utilizariam.

Na quinta e última questão, investigou-se qual a conotação, positiva ou negativa, que as formas de representação da cruz exerciam sobre os participantes; foi solicitado que justificassem suas respostas.

Dentre os respondentes, $19 \%$ disseram ter uma percepção negativa; 35\%, positiva; $38 \%$ responderam que a percepção dependia do contexto; e $8 \%$, ambas.

\section{Justificativas para a conotação negativa:}

Alguns consideraram que o símbolo da cruz remete à morte e citaram o exemplo das cruzes que são fixadas na beira de estradas; outros a associaram a: penitência, peso, doença, hospitais, ambulâncias, sacrifícios (citaram a suástica). 
Para os que se identificaram como cristãos, a cruz lembra o sofrimento de Jesus.

Para outros, a cruz remete ao fanatismo religioso.

A cruz pode ser um símbolo de exclusão, se utilizada num meio em que nem todos compactuam da mesma ideologia, conforme alguns dos participantes.

\section{Justificativas para a conotação positiva:}

Alguns a relacionaram positivamente, na utilização de acessórios ligados ao mundo da Moda. Outros, que se identificaram cristãos, associaram a cruz à representação da salvação;

Alguns destacaram a sua utilização em programas de ajuda humanitária, da área da saúde e em campanhas de solidariedade.

Outros disseram tratar-se de um símbolo simétrico, que transmite leveza e sugere o formato de um corpo humano.

Obs.: Vale ressaltar que os participantes que responderam que os símbolos da cruz transmitiam ambas as conotações, positiva e negativa, ou que a percepção dependia do ponto de vista, quando possível, tiveram suas justificativas encaixadas nas justificativas acima.

\section{Considerações Finais}

Apesar do símbolo da cruz ter inúmeras formas de representação, as mais lembradas pelos participantes foram: a Cristã, a Suástica e a Simples, hoje utilizada como representação gráfica do símbolo de adição. Isto se deve ao impacto que os movimentos culturais exerceram sobre a sociedade. $\mathrm{O}$ fato de todos os participantes serem brasileiros subentende que todos têm uma bagagem de conhecimento sobre o cristianismo, mesmo que não façam parte desta ideologia. Com relação à suástica, por esta ter sido utilizada em um movimento de repercussão mundial muito chocante, evento que faz parte do currículo de História das escolas do ensino fundamental e médio, é muito lembrada e discutida entre as pessoas.

Apesar de a cruz ser um símbolo antigo, perpetua-se a sua utilização, nos dias atuais, no meio comunicacional, não apenas religioso, mas em algumas mídias seculares. Vários designers a tem utilizado em logos, brasões, materiais gráficos, entre outros.

A utilização de símbolos no design pode ser um ótimo aliado para se gerar sensações, boas ou chocantes, nos receptores, porém, deve-se ter a preocupação de transmitir a sensação adequada, atentando-se para o objetivo proposto, sem que haja ambiguidade.

A cruz é um símbolo que não tem o poder de gerar uma única conotação, devido aos fatores histórico-culturais transmitidos, de geração em geração, às pessoas, porém, é um símbolo que consegue apresentar duas sensações extremamente diferentes ao mesmo público, dependendo da forma que for inserida e apresentada.

\section{Notas}

1 Disponibilizado em: http://uniware.com.br/instala/files/mariana.html

2 Retirado do Dicionário Houaiss da língua portuguesa.

3 Retirado do site: http://www.spectrumgothic.com.br/ocultismo/simbolos/cruz_simbolismos.htm Acesso em: 21 ago. 2010

4 Retirado do site: http://www.spectrumgothic.com.br/ocultismo/simbolos/cruz_simbolismos.htm Acesso em: 21 ago. 2010

\section{Referências}

AUMONT, J. A imagem. 2. ed. Campinas: Papirus, 1995. 317p. 
CARRION, W. Design para webdesigners: princípios do design para web. Rio de Janeiro: Brasport, 2008.167p.

CHEVALIER, J.; GHEERBRANT, A. Dicionário de símbolos: mitos, sonhos, costumes, gestos, formas, figuras, cores, números. 9ed. Rio de Janeiro: José Olympio, 1995. 996p.

CIRLOT, J. E.. A dictionary of symbols. 2ed. London: Routledge, 1990. 419p.

FLUSSER, V. (1920-1991). O mundo codificado: por uma filosofia do design e da comunicação: Vilém Flusser; organizado por Rafael Cardoso. Tradução Raquel Abi-Sâmara. São Paulo: Cosac Naify, 2007. 224p.

FRUTIGER, A. Sinais e símbolos: desenho, projeto e significado. Tradução Karina Jannini. São Paulo: Martins Fontes, 1999.334p.

HOUAISS, Antonio; VILLAR, Mauro de Salles; FRANCO, Francisco Manoel de Mello. Dicionário Houaiss da língua portuguesa. Rio de Janeiro: Objetiva, 2001. 2.922p.

HURLBURT, A. Layout: o design da página impressa. Tradução Edmilson O. Conceição, Flávio M. Martins. São Paulo: Nobel, 2002

JUNIOR, Eduardo Neiva. A imagem. São Paulo: Ática, 1986. 93p.

LARAIA, R. de. B. de. (1932). Cultura uni conceito antropológico. 22 ed.

Rio de Janeiro: Jorge "Zahar" Ed. 2008. 117p.

LUCCA, G. A cruz e seus simbolismos. Disponível em <http://www.spectrumgothic.com.br/ocultismo/ simbolos/cruz_simbolismos.htm>. Acesso em: 24 out. 2010.

LUPTON, E. Novos fundamentos do design: São Paulo: Cosac Naify, 2008, 248p.

MELO, C. H. de. Signofobia. São Paulo: Rosari, 2005, (Coleção Textos Design). $112 \mathrm{p}$.

MOURA, M. Faces do design. São Paulo: Rosari, 2003 (Coleção Textos Design). 146p.

SANTAELLA, L. O que é semiótica. São Paulo: Brasiliense, 1983

(Coleção Primeiros Passos). 82p.

SCHNEIDER, B. Design - Uma introdução: o design no contexto social, cultural e econômico. São Paulo: Blucher, 2010. 304p

STOLARSKI, A. Alexandre Wollner e a formação do design moderno no Brasil. São Paulo: Cosac \& Naify, 2005.

VILLAS-BOAS, A. (1963). Identidade e Cultura. Rio de Janeiro: 2AB, 2002. 120p. 